\title{
Wind tunnel investigation on the dust emission characteristics of high moisture coal piles
}

\author{
Ningning Hong ${ }^{1}$, Shitao Peng ${ }^{1}$, Hongxin $\mathrm{Zhao}^{1}$ and Ning $\mathrm{Su}^{1 *}$ \\ ${ }^{1}$ Tianjin Research Institute for Water Transport Engineering, Ministry of Transport of the People's Republic of China, Tianjin 300456, \\ China
}

\begin{abstract}
With the increasing requirements of environmental protection, a large number of new wet dust suppression technologies are used in the port in recent years, such as watering at the bottom of the Dumper Shed, etc. So the moisture content of coal is more than $10 \%$ often appear. Relevant studies show that the amount of dust from coal (conventional moisture content) pile is directly proportional to the high power of wind speed. But studies on high moisture content coal are rare. In this study, Wind tunnel test was carried out to study the dust emission behavior of coal with high moisture content (13.7\% and $14.3 \%)$. The results show that the relationship between coal dust and wind speed tends to be linear under high moisture content. The study can provide a basis research for the estimation of coal dust emission in port.
\end{abstract}

\section{Introduction}

The diffusion and migration of cargo dust in the atmospheric environment constitutes one of the main components of air particulate pollution in coastal cities [1 2]. The static dust volume of bulk cargo yard is mainly related to wind speed and the physical characteristics of the material itself, such as moisture content ${ }^{[3 \sim 5]}$. The common conclusion of the existing researches the amount of dust from coal(conventional moisture content) pile is directly proportional to the high power of wind speed while the parameter value is different ${ }^{[6-8]}$. In previous studies, the coal moisture content interval was generally lower than $10 \%$.

With the increasing requirements of environmental protection, especially from the environmental protection tax law of the People's Republic of China came into effect on January 1, 2018, the requirements for dust pollution control in ports are also increasing, In order to reduce the environmental protection tax, many bulk ports have developed the technological transformation of environmental protection equipment. In order to reduce the static dust of coal in the bulk yard, some bulk ports adopt the technology of watering at the bottom of the Dumper Shed, watering from the cantilever of the stacker, etc. With the applications of these technologies, the moisture content of coal has been greatly increased compared with the past, and the moisture content of coal is often higher than $10 \%$. As for the dust emission characteristics of high moisture coal, there is rare relevant research. In this study, wind tunnel tests were carried out to investigate the dust emission characteristics of high moisture coal piles. The study can provide a basis for the estimation of coal dust emission in port area.

\footnotetext{
$\overline{\text { *Corresponding author's e-mail: souvenire } @ 126 . c o m}$
}

\section{Wind tunnel test}

\subsection{Test equipment, samples and models}

\subsubsection{Test equipment}

The test was carried out in the TKS-1 atmospheric boundary layer wind tunnel of Tianjin Research Institute for Water Transport Engineering, M.O.T. The wind tunnel is a horizontal, open-circuit, blow-out, and single-test wind tunnel. The size of the test section is 4.4 meters in width, 2.5 meters in height and 15 meters in length. The designed maximum wind speed of empty tunnel in the test section is $30 \mathrm{~m} / \mathrm{s}$. Uniform wind field simulation was used in this test.

\subsubsection{Test samples}

The coal pile model is reduced in a certain geometric scale, but the geometric size of the model particles is the same as prototype. Because the particle size is a decisive variable during the start-up, migration and sedimentation procedures. And geometric reduction is not appropriate and feasible in wind tunnel simulation experiments. There is a geometric upper bound in the simulation for the larger solid masses. According to relevant research experience, the upper limit of the geometric size can be set as $2 \mathrm{~mm}$.

The test materials in this wind tunnel test is the main coal in a coal port: $\mathrm{S}$ and $\mathrm{D}$. S represents coal samples with more fine particles, while D represents coal samples with more coarse particles. Two kinds of coal with mixed gradation were selected as test materials. In the test, large 
particles larger than $2 \mathrm{~mm}$ were removed through screening, and the remaining particles were fully stirred. The particle size distribution of the two coal samples is shown in Figure 1. The mass fraction of large particle size $(>1000 \mu \mathrm{m})$ of $\mathrm{D}$ is greater than that of $\mathrm{S}$.

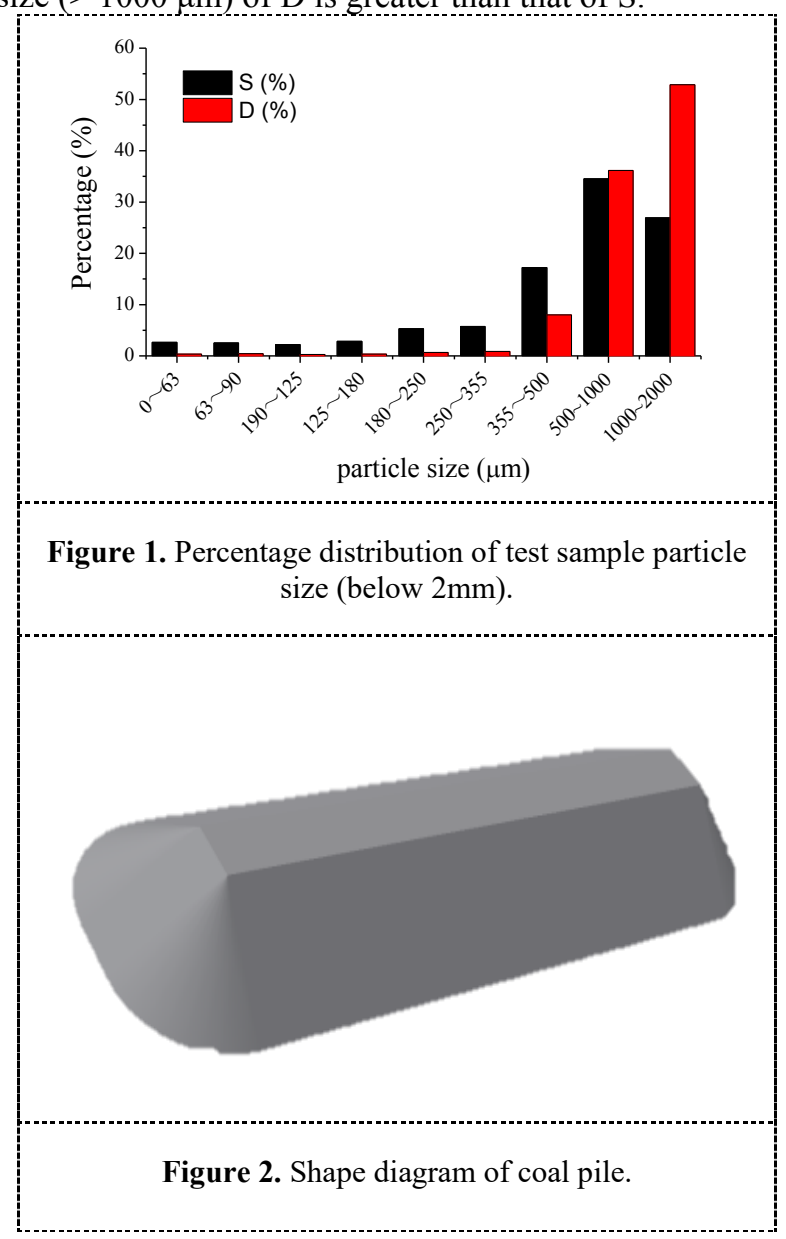

\subsubsection{Test model}

In the test, the coal was stacked on a single pile, and the size and shape of the pile were determined according to the design scale and shape of the actual flat-topped pile in the coal wharf yard according to the 1:200 scale. Stack shape diagram is shown in Figure 2. The prototype stacking base is $120 \mathrm{~m}$ in length, $44 \mathrm{~m}$ in width, $37^{\circ}$ resting angle and $13.5 \mathrm{~m}$ high.

\subsection{Test method}

\subsubsection{Determination of the moisture content of sample}

The test coal samples are divided into natural moisture content and high moisture content. In this test, the natural moisture content is defined as the moisture content of coal samples which taking from the storage to the test hall for spreading, turning and airing for two weeks until the moisture content is stable. High moisture content samples were stored in double sealed test bags.

The test samples are weighed and put into the drying oven at low temperature $\left(40^{\circ} \mathrm{C}\right)$ for more than 24 hours.
After sealed weighing records, the samples are put into the drying box for further drying. After 1 hour, the samples are weighed again. When the mass difference between two weighings is less than one thousandth of the weight of the sample, it can be considered that the sample has been dried to the water free state. The moisture content of samples can be calculated by weight difference before and after drying. The moisture content can be calculated by equation (1).

$$
w=\frac{m_{b}-m_{a}}{m_{b}} \times 100 \%
$$

Where $w$ is the moisture content in $\% ; m_{b}$ is the weight of coal sample before dring in $\mathrm{g} ; m_{a}$ is the weight of coal sample after dring in $\mathrm{g}$.

\subsubsection{Determination of the threshold velocity of coal dust}

The coal to be measured is evenly spread out to avoid surface wrinkles as far as possible, and the focal length and geometric magnification of the observation equipment in the wind tunnel are adjusted to obtain the clearest image. Start the wind tunnel fan, gradually increase the wind speed, and observe the movement of particles. The particle is considered to have started up when the rolling of the particle is obvious. The process is repeated several times to obtain the mean values of the threshold velocity of coal dust.

\subsubsection{Dust emission characteristics and test cases}

Before the test, clean the wind tunnel to reduce the experiment error. The test samples were stacked according to the size requirements of the stack on the rimless tray, and then the tray and the stack were weighed and placed in the wind tunnel. In order to obtain the most adverse dust amount, the direction of the short axis of the stack is consistent with the wind direction, so as to maximize the windward side, as shown in Figure 3. After testing in the wind tunnel, the stack and the tray were weighed. And the difference between the weight and the weight before the test is the amount of dust. The preliminary test was conducted to determine the test time length. The preliminary test showed that the wind erosion rate of the two types of coal decreased rapidly with time at the beginning of the test, and the change slowed down after $15 \mathrm{~min}$, so the wind erosion time of the test was determined to be $15 \mathrm{~min}$. The test cases of two kinds of coal, two moisture contents and five test wind speeds were studied. The test wind speeds were set as 3, 5, 7, 9 and $11 \mathrm{~m} / \mathrm{s}$. The moisture content can be calculated by equation (2).

$$
Q=M_{b}-M_{a}
$$
where $Q$ is the dust volume of the coal stack in $\mathrm{g} ; M_{b}$ is the weight of coal stack and the tray before testing in $g$; $M_{a}$ is the weight of coal stack and the tray after testing in g. 


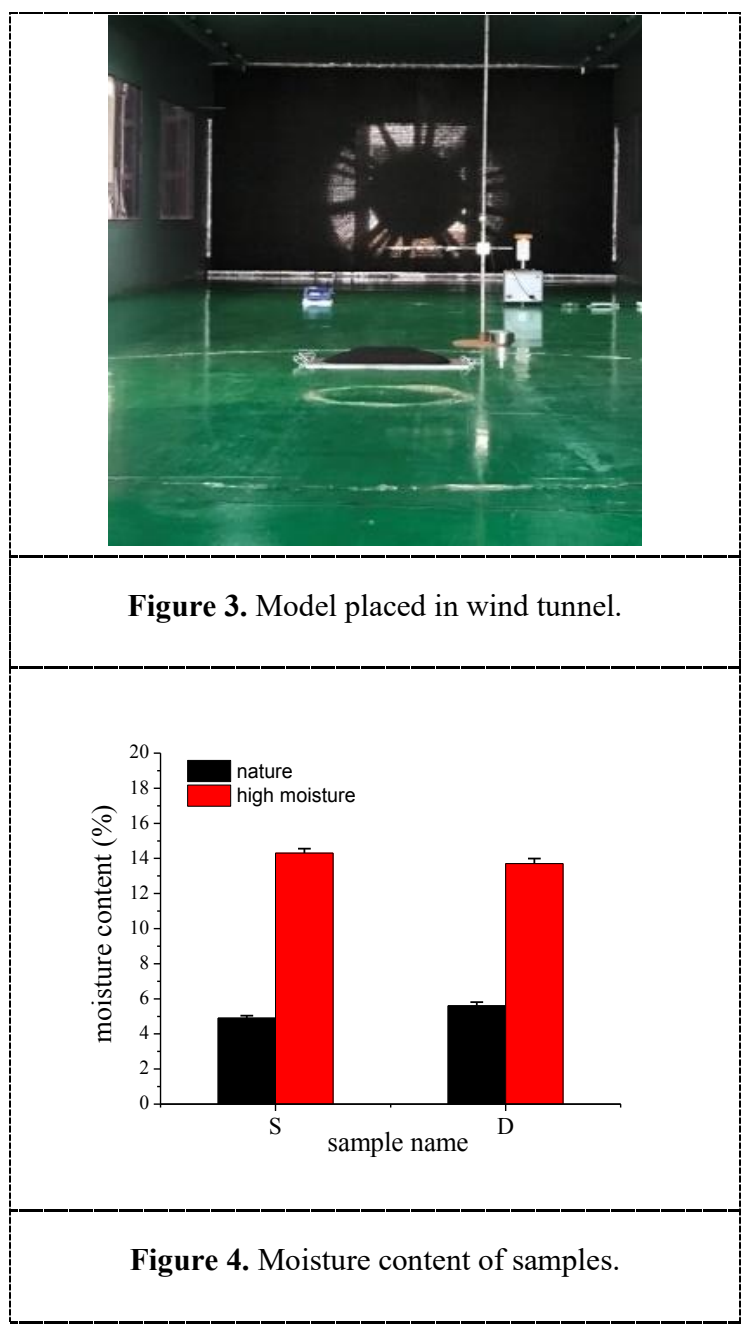

\section{Result analysis}

\subsection{Moisture content}

The test results for determination of the moisture content of sample are shown in Figure 4. The results show that the natural moisture content of the two coal samples ranges from $4.7 \%$ to $5.9 \%$, with mean values of $4.9 \%$ and $5.6 \%$, which are close to each other. The moisture content mean values of high moisture content samples were $14.3 \%$ and $13.7 \%$, respectively.

\subsection{Threshold velocity}

The threshold velocity of the natural moisture content coal dust is shown in Figure 5. The experimental results show that the change of the threshold velocity of the two kinds of coal dust is basically the same. Although the proportion of particles with different sizes is different in the two samples. However, the minimum dust particle size that can be observed is similar with the same observation state (same test equipment, personnel and environment), which has nothing to do with the content of the particle size in coal. Therefore, the observed threshold velocity is similar, and the fluctuation of the data is only the experimental error.

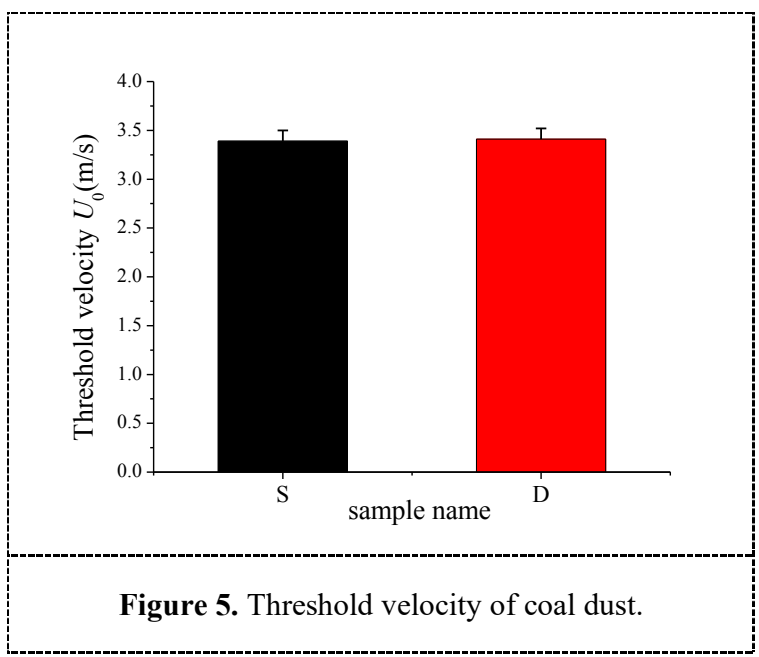

\subsection{Dust emission characteristics}

The calculation model recommended in Specifications for Environmental Impact Assessment of Port Engineering (JTS 105-1-2011) was adopted. The calculation model is shown in equation (3).

$$
Q_{1}=0.5 \alpha\left(U-U_{0}\right)^{3} S
$$

where $Q_{1}$ is the dust volume of the yard in $\mathrm{g} \cdot \mathrm{s}^{-1} \cdot \mathrm{m}^{-2} ; \alpha$ is the dust regulation coefficient of cargo type; $U$ is the test wind speed in $\mathrm{m} / \mathrm{s} ; U_{0}$ is the threshold velocity of mixed particle size $(\mathrm{m} / \mathrm{s}) ; S$ is the surface area in $\mathrm{m}^{2}$.

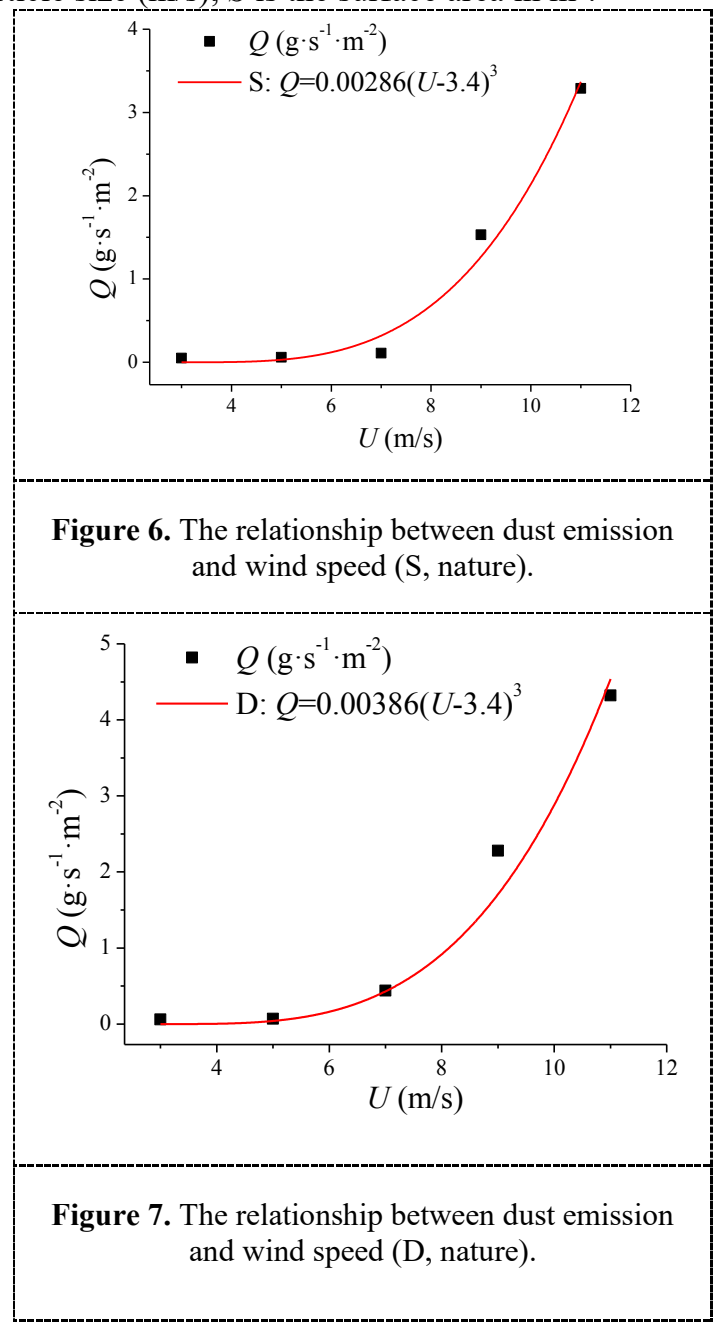


The fitting results of the relationship between dust volume and wind speed of the two types of natural moisture content coal are shown in Figure 6-7. The fitted $\mathrm{R}$-square of S coal is 0.9849 , and the fitted R-square of D coal is 0.9723. It can be seen that dust emission is approximately proportional to the third power of wind speed.

The fitting results of the relationship between dust volume and wind speed of the two types of high moisture content coal are shown in Figures 8 and 9. It is found that the relationship is far from the cubic of wind speed. And it is more linear by observing the distribution of data points. So linear fitting is carried out. And the fitting result is shown as the blue line. The linear fitting formula of dust amount of $\mathrm{S}$ coal and wind speed is $Q=$ $0.0195 U+0.0715$, and the R-Square is 0.9767. The linear fitting formula of dust amount of coal type D and wind speed is $Q=0.034 U+0.042$, and the R-Square is 0.9674 .

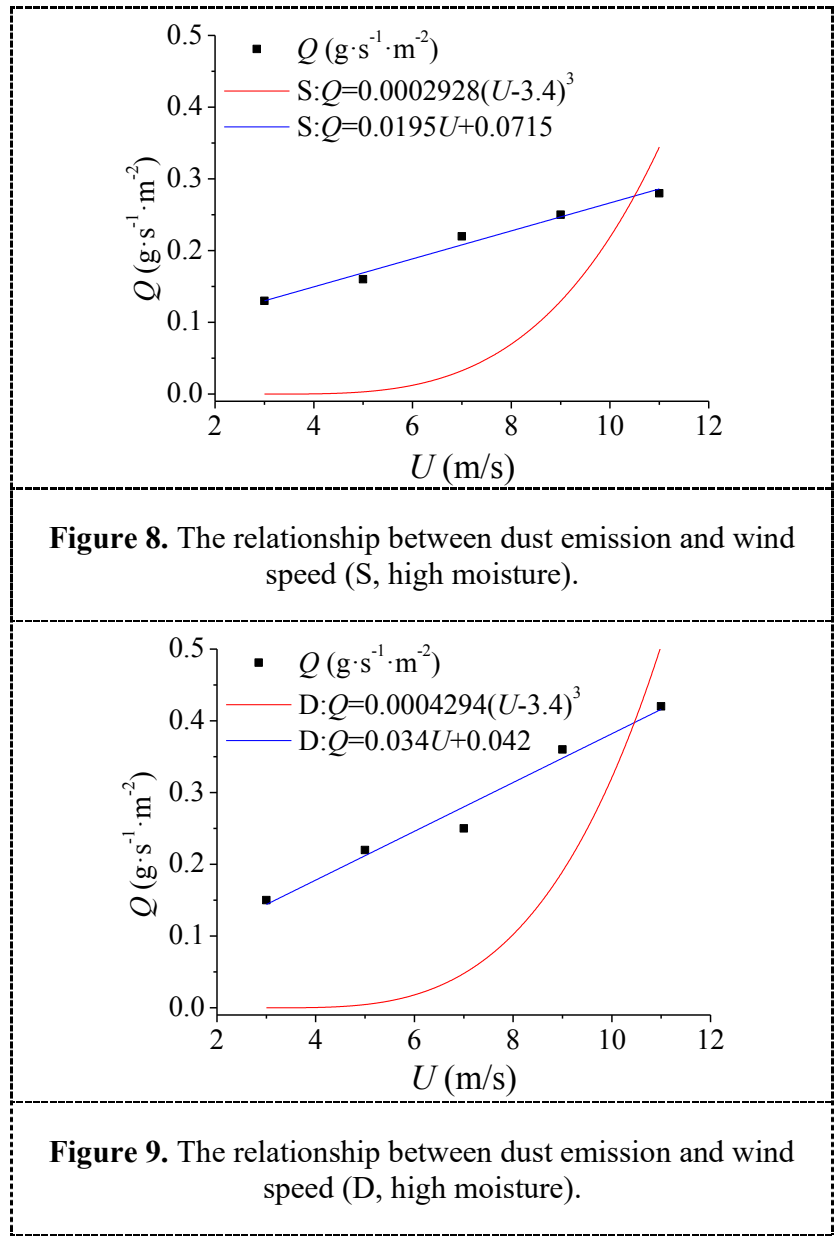

\section{Conclusions}

(1) The research shows that the relationship between coal dust and wind speed in high moisture content coal is rather high power but linear. The linear fitting formula of dust amount of $\mathrm{S}$ coal and wind speed is $Q=$ $0.0195 U+0.0715$, and the R-Square is 0.9767 . The linear fitting formula of dust amount of coal type $\mathrm{D}$ and wind speed is $Q=0.034 U+0.042$, and the R-Square is 0.9674 . The study can provide a basis research for the estimation of coal dust in port.

(2) For either S coal or D coal, the dust volume of static stack is significantly reduced with the high moisture content. In other words, the dust control method of temporarily watering the stacking surface can also be adopted before the coming of a strong wind.

(3) It is easy to cause additional test error due to the rapid loss of water in the high moisture content coal sample. In a follow-up study will further improve test method to realize accurate simulation of the relationship between high moisture content coal dust amount and wind speed.

\section{Acknowledgements}

This research has been supported by the China National Key R\&D Program (Grant No. 2016YFE0204800), Tianjin Transportation Science and Technology Development Project (Grant Nos. 2018-b4, 2019-11) and the Fundamental Research Funds for the Central Public Welfare Research Institutes (Grant No. TKS190204).

\section{References}

1. Wu W P. (2003) Prevention \& Control Strategies and It's Exsiting Status for Dust Pollution in Chinese Harbour. Journal of Traffic and Environmental Protection, 22(4): 380-384.

2. Lu Q X, Hong N N, Zhan S F, et al. (2008) Research progress on prevention and control technologies of dust pollution in ports. Journal of Waterway and Harbor, 29(6): 451-452.

3. Fabiano B, Curro F, Reverberi A P, et al. (2014) Coal dust emissions: From environmental control to risk minimization by undergroundtransport. An applicative cases study. Process safety and environment protection, 92:150-159.

4. Dale G. (1978) A wind tunnel simulation of the erosion of soil: effect of soil texture, sandblasting, wind speed and soil consolidation on dust production. Atmospheric Environment, 12(8): 1735-1743.

5. Li S W, Li W S, Lei P, et al. (2016) Research on dust emission of iron ore for bulk cargo yard of ore terminal by using wind tunnel test. Journal of Waterway and Harbor, 37(5): 558-562

6. Xuan J, Robins A. (1994) The effects of turbulence and complex terrain on dust emissions and depositions from coal stockpiles. Atmospheric Environment, 28(11): 1951-1960.

7. Xuan J, An W P, Wang X Y, et al. (1992) Influence of atmospheric boundary layer turbulence and complex terrain on dust emission from coal piles and distribution of failing dust. China environment science, 12(4): 261-266.

8. Wang X F, Liu Q, Tang Z G, et al. (1987) Wind tunnel test of dust pollution. Environmental Science, 8(6): 21-25. 